\title{
Analysis of Broadband L-probe Fed Microstrip Antennas
}

\author{
Amit A. Deshmukh \\ EXTC, DJSCOE \\ Vile - Parle (W), \\ Mumbai, India
}

\author{
Rakesh Jondhale \\ EXTC, DJSCOE \\ Vile - Parle (W), \\ Mumbai, India
}

\author{
Ishitva Ajmera \\ EXTC, DJSCOE \\ Vile - Parle (W), \\ Mumbai, India
}

\author{
Neelam Phatak \\ EXTC, DJSCOE \\ Vile - Parle (W), \\ Mumbai, India
}

\begin{abstract}
Broadband suspended microstrip antenna on thicker substrate is realized by using non-contact L-probe feeding technique. The guidelines for selecting total L-probe length are not available in the reported literature. In this paper, an analysis of broadband L-probe fed variations of microstrip antenna like, circular microstrip antenna, annular ring microstrip antenna, rectangular microstrip antenna, E-shaped microstrip antenna and half E-shaped microstrip antenna, is presented. It was observed that, total L-probe feed length nearly equals quarter wavelength at the resonance frequency of equivalent patch. Further using this quarter wavelength approximation, L-probe fed rectangular and circular microstrip antennas were redesigned at different frequencies which results into the broadband response with formation of loop inside the VSWR $=2$ circle. The comparison between two non-contact feeding techniques of microstrip antenna, namely proximity feed and L-probe feed is presented. The two have similar performance in terms of bandwidth and radiation pattern, with proximity feeding technique to be the simplest method to be implemented in thicker substrates.
\end{abstract}

\section{Keyword}

Rectangular microstrip antenna, Circular microstrip antenna, Annular ring microstrip antenna, E-shaped microstrip antenna, Broadband microstrip antenna, L-probe feed

\section{INTRODUCTION}

The simplest method to realize broadband microstrip antenna (MSA) is by fabricating the patch on lower dielectric constant thicker substrate [1 - 3]. In most of the reported literature, the patch is suspended in air thereby realizing dielectric constant of unity. For substrate thickness greater than 0.04 to $0.05 \lambda_{0}$, the antenna BW is limited by the feed probe inductance, since the input impedance locus for the same cannot be optimized inside the VSWR $=2$ circle. Using substrate thickness more than $0.05 \lambda_{0}$, the antenna $\mathrm{BW}$ is increased by using different feeding techniques like, L-probe feed and proximity feed [4 9]. These feeding techniques are simpler to be implemented in thicker substrates. The BW of MSA is also increased by cutting the slot at an appropriate position inside the patch and these slot cut MSAs are optimized on substrate of thickness 0.06 to $0.08 \lambda_{0}[10-15]$. To optimize them on substrates with thickness more than $0.08 \lambda_{0}$, the proximity feeding as well as L-probe feeding has been used $[4,9,16]$. In proximity feeding, a coupling strip is placed below the radiating patch and through the electromagnetic coupling between patch and strip, a broadband response is realized. The design guidelines for coupling strip dimension for rectangular MSA (RMSA), circular MSA (CMSA) and equilateral triangular MSA (ETMSA) are reported [17]. In L-probe feeding the broader bandwidth (BW) is realized due to electromagnetic coupling between horizontal section of the L-probe strip and the patch mode. Also in L-probe feeding the realized BW also depends upon the ratio of vertical strip length to its horizontal length for the given patch substrate thickness. The design guidelines for properly selecting the strip vertical and horizontal lengths are not reported in the available literature. In this paper, various reported broadband designs of L-probe fed RMSA, Uslot cut CMSA, annular ring MSA, E-shaped MSA and half E-shaped MSAs are discussed. Further using their optimized designs the formulation for total L-probe length in terms of operating wavelength of the resonance frequency of the radiating patch is proposed. The total L-probe length was found to be around quarter wave in length at the patch resonance frequency. Using this approximation, RMSAs and CMSAs were re-designed at different frequencies. This results in broader BW with formation of loop in the impedance locus inside the VSWR $=2$ circle. For RMSA, the comparison between the non-contact proximity feeding and L-probe feeding technique is presented. It was observed that in terms of operating BW and radiation pattern characteristics, both these techniques yields nearly the same performance, however as against L-probe feeding, the proximity feeding is simpler to implement especially in thicker substrates. The proposed study was carried out using IE3D software [18] and to validate the simulated results, measurements were carried out using finite square ground plane of side length $40 \mathrm{~cm}$. The input impedance response was measured using $\mathrm{R} \& \mathrm{~S}$ vector network analyzer.

\section{L-PROBE FED MSAs}

The L-probe fed RMSA is shown in Fig. 1(a, b) [5]. The antenna is fabricated on RT-duroid substrate of thickness 0.16 $\mathrm{cm}$, and it is suspended above the ground plane with an air gap of $1 \mathrm{~cm}$ [5]. This gives total substrate thickness of 1.16 $\mathrm{cm}$ (i.e. $\left.0.087 \lambda_{0}\right)$. The optimized return loss plot $\left(S_{11}\right)$ for this antenna is shown in Fig. 1(c) [5] and its VSWR $<2$ BW is from 1920 to $2510 \mathrm{MHz}$ (26\%). The optimized configuration is simulated using IE3D software and its resonance curve plot is shown in Fig. 1(d). It shows peak at $2250 \mathrm{MHz}$ due to $\mathrm{TM}_{10}$ mode of RMSA. The total L-probe strip length in optimized configuration is, $1_{\text {eff }}\left(\mathrm{HF}_{\mathrm{L}}+\mathrm{H}+\mathrm{t}\right)=2.31 \mathrm{~cm}$. To this length the fringing field extension towards an open circuit edge of $\mathrm{L}$ probe feed is added, ( $\sim 0.75$ to 0.8 times total substrate thickness) [3, 17]. Further $1_{\text {eff }} / \lambda_{0}$ for this configuration is calculated and it equals 0.243 , which is nearly quarter wave length at the RMSA resonance frequency.

The L-probe fed U-slot cut CMSA is shown in Fig. 2(a, b) [6]. For patch thickness of $1.16 \mathrm{~cm}$, L-probe feed thickness of $0.76 \mathrm{~cm}$, U-slot cut CMSA is simulated using IE3D software and its input impedance plot and resonance curve plots for different U-slot lengths are shown in Fig. 2(c, d). The U-slot reduces the resonance frequency of second order mode of CMSA and along with its first order mode yields simulated $\mathrm{BW}$ of $1253 \mathrm{MHz}(\sim 32 \%)$ [6]. The resonance curve plot for optimum configuration $\left(\mathrm{L}_{\mathrm{b}}=1.4 \mathrm{~cm}, \mathrm{~L}_{\mathrm{s}}=1.6 \mathrm{~cm}\right)$ shows three peaks at 3124, 3424 and $4396 \mathrm{MHz}$. The surface currents at 
first two peaks show variations due to modified $\mathrm{TM}_{11}$ modes of circular patch whereas at third peak, surface currents due to modified second order mode (slot mode) are present. The total L-probe length in this configuration is $2.718 \mathrm{~cm}$, which is 0.283 times the operating wave length at first peak i.e. due to the patch mode. Thus in this case also L-probe length equals nearly quarter wave in length.
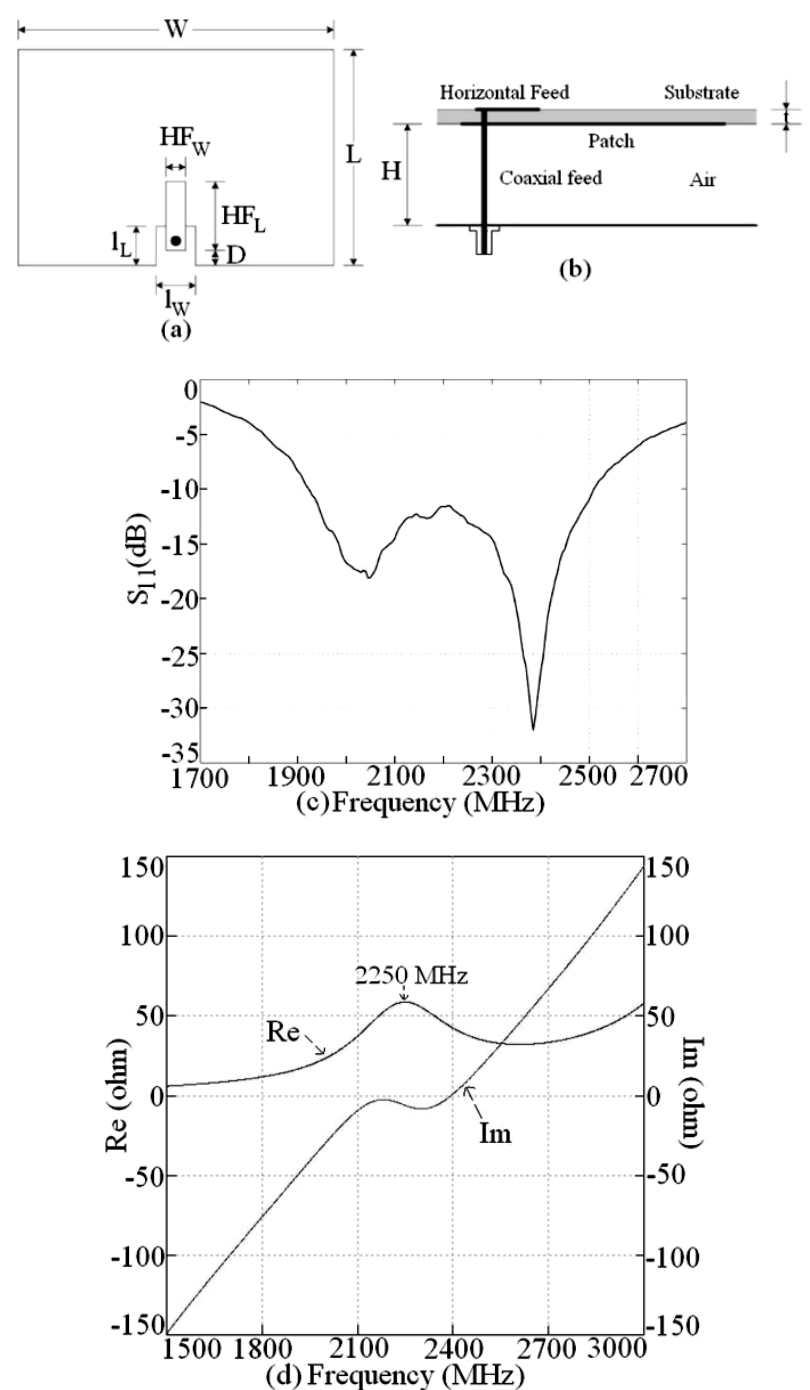

Fig. 1 (a) Top and (b) side views of L-probe fed RMSA, its (c) measured $S_{11}$ plot [5] and its (d) simulated resonance curve plot

The L-probe fed annular ring MSA is shown in Fig. 3(a, b) [7]. The annular ring MSA is optimized for broader BW at its $\mathrm{TM}_{11}$ and $\mathrm{TM}_{21}$ modes [7]. At $\mathrm{TM}_{11}$ mode, antenna impedance BW is from 3080 to $3920 \mathrm{MHz}$ (24\% centered at $3500 \mathrm{MHz}$ ) as shown in Fig. 3(c). The total L-probe feed length in the optimized configuration is $1.7+0.6=2.3 \mathrm{~cm} \mathrm{[7]}$. To this length additional length due to fringing field extension towards the open circuit edge of L-probe feed is added, and the total L-probe feed length equals 0.3 times the operating wavelength at the resonance frequency of annular ring MSA.

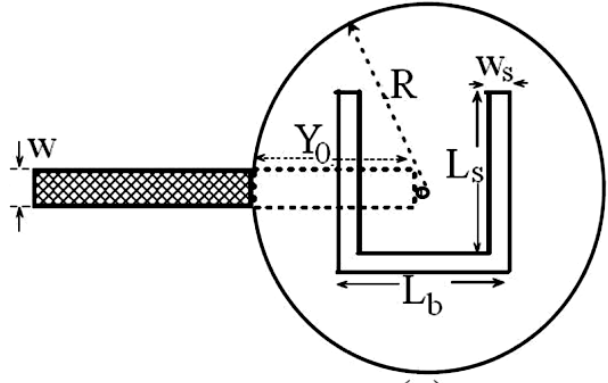

(a)

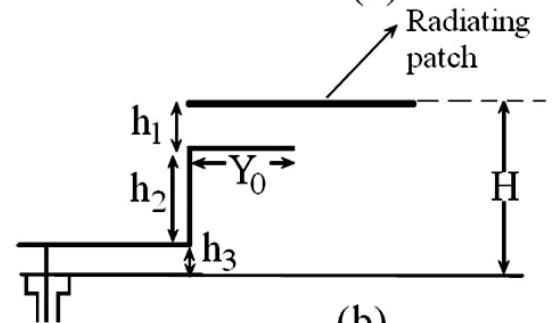

(b)

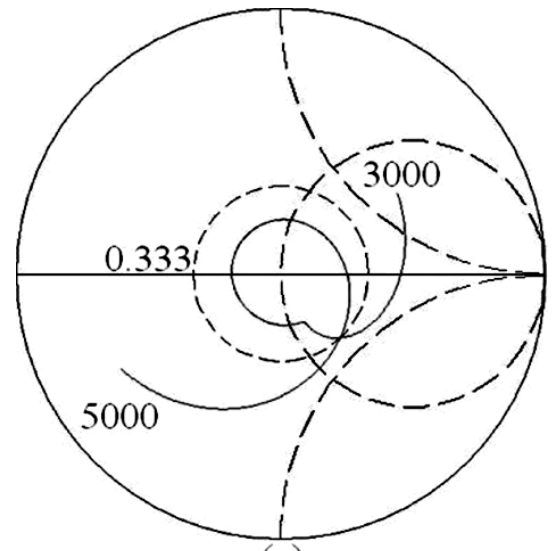

(c)

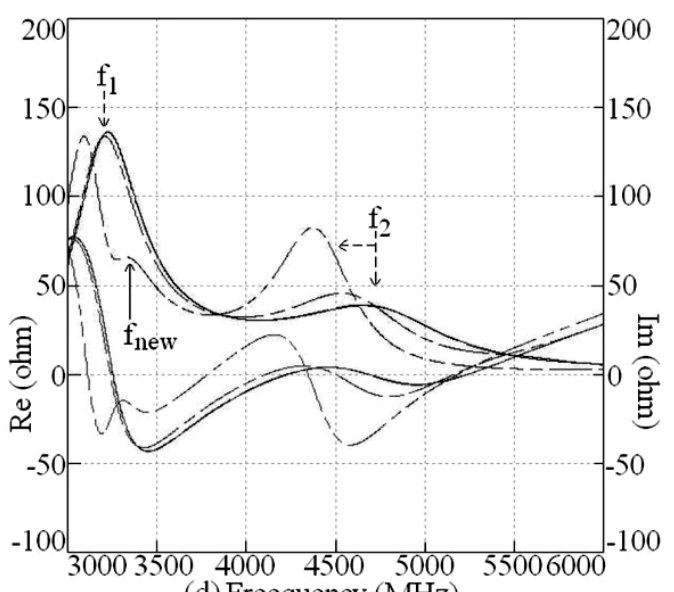

(d) Freequency $(\mathrm{MHz})$

Fig. 2 (a) Top and (b) side views of L-probe fed U-slot cut CMSA [6] and its simulated (c) input impedance and (d) resonance curve plots, $(-) \mathrm{CMSA},(--) \mathrm{L}_{\mathrm{b}}=1.4 \mathrm{~cm}$, $(--\square) \mathrm{L}_{\mathrm{b}}=1.4 \mathrm{~cm}, \mathrm{~L}_{\mathrm{s}}=1.0 \mathrm{~cm},(--\square) \mathrm{L}_{\mathrm{b}}=1.4 \mathrm{~cm}, \mathrm{~L}_{\mathrm{s}}$ $=1.6 \mathrm{~cm}$ 


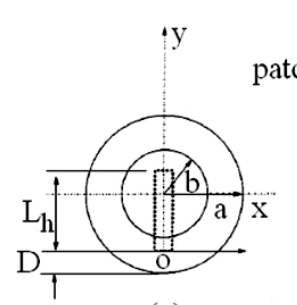

(a)

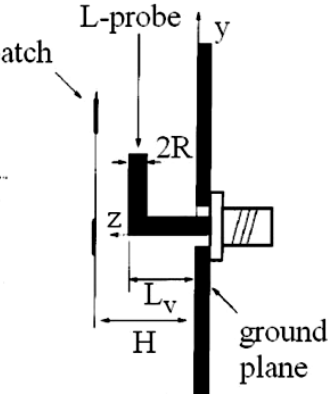

(b)

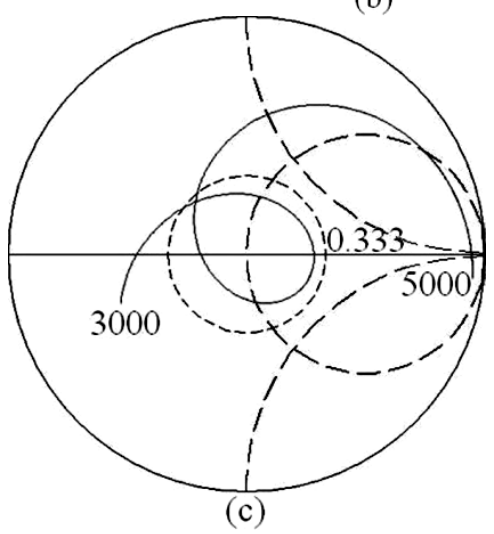

Fig. 3 (a) Top and (b) side views of L-probe fed Annular ring MSA [7] and its (c) simulated input impedance plot

The broadband L-probe fed E-shaped and half E-shaped MSAs is shown in Fig. 4(a-d). In E-shaped and half Eshaped MSAs, rectangular slots reduces the resonance frequency of higher order orthogonal $\mathrm{TM}_{02}$ and $\mathrm{TM}_{01}$ modes, respectively, of equivalent RMSA, and along with its $\mathrm{TM}_{10}$ mode, yields broadband response [19]. The L-probe fed Eshaped MSA yields simulated and measured BW of nearly $200 \mathrm{MHz}(>20 \%)$ whereas L-probe fed half E-shaped MSA yields BW of more than $170 \mathrm{MHz}(\sim 18 \%)$ as shown in Fig. $4(e, f)$. The resonance curve plots for the optimized E-shaped and half E-shaped MSAs are shown in Fig. 4(g). The two peaks in respective resonance curve plots are present due to $\mathrm{TM}_{10}$ and modified $\mathrm{TM}_{02}$ and $\mathrm{TM}_{01}$ modes. With respect to $\mathrm{TM}_{10}$ mode, total L-probe length (including fringing field extension length) equals $0.28 \lambda_{0}$ in E-shaped MSA whereas it equals $0.29 \lambda_{0}$, in half E-shaped MSA. Thus as observed in above most of the reported L-probe fed MSAs, total probe length nearly equals quarter wave in length.

Further using nearly quarter wavelength approximation, Lprobe fed RMSA and CMSA are designed at different frequencies. The RMSA is designed at its $\mathrm{TM}_{10}$ mode frequency of $900 \mathrm{MHz}, 1500 \mathrm{MHz}, 2000 \mathrm{MHz}$ and 3000 MHz. At each frequency the RMSA is suspended in air with substrate thickness of $0.08 \lambda_{0}$, and L-probe is kept below the patch with its vertical length to be $0.073 \lambda_{0}$. The horizontal Lprobe length is optimized by considering the fringing field extension length, to realize broadband response. The optimized simulated input impedance plots at each of the above frequencies are shown in Fig. $5(\mathrm{a}, \mathrm{b})$ and results for them are summarized in Table 1. Similarly L-probe fed CMSAs is optimized for broader BW at two different frequencies and its input impedance plots are shown in Fig. 5(c). The results for the same are summarized in Table 1. In all the MSAs, using L-probe length nearly equal to quarter wave in length, a broadband response with formation of loop inside the VSWR = 2 circle has been realized.

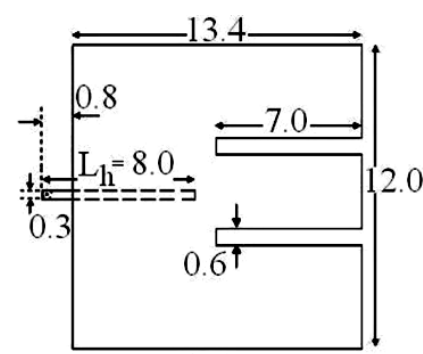

(a)
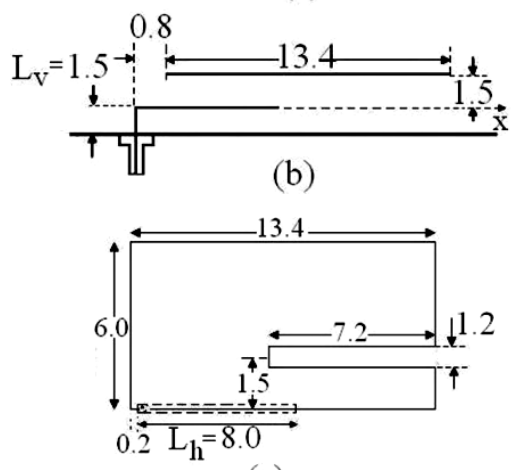

(c)

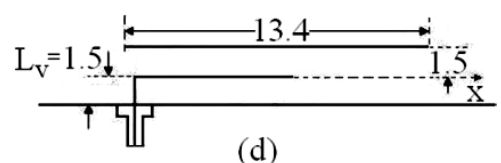

(d)
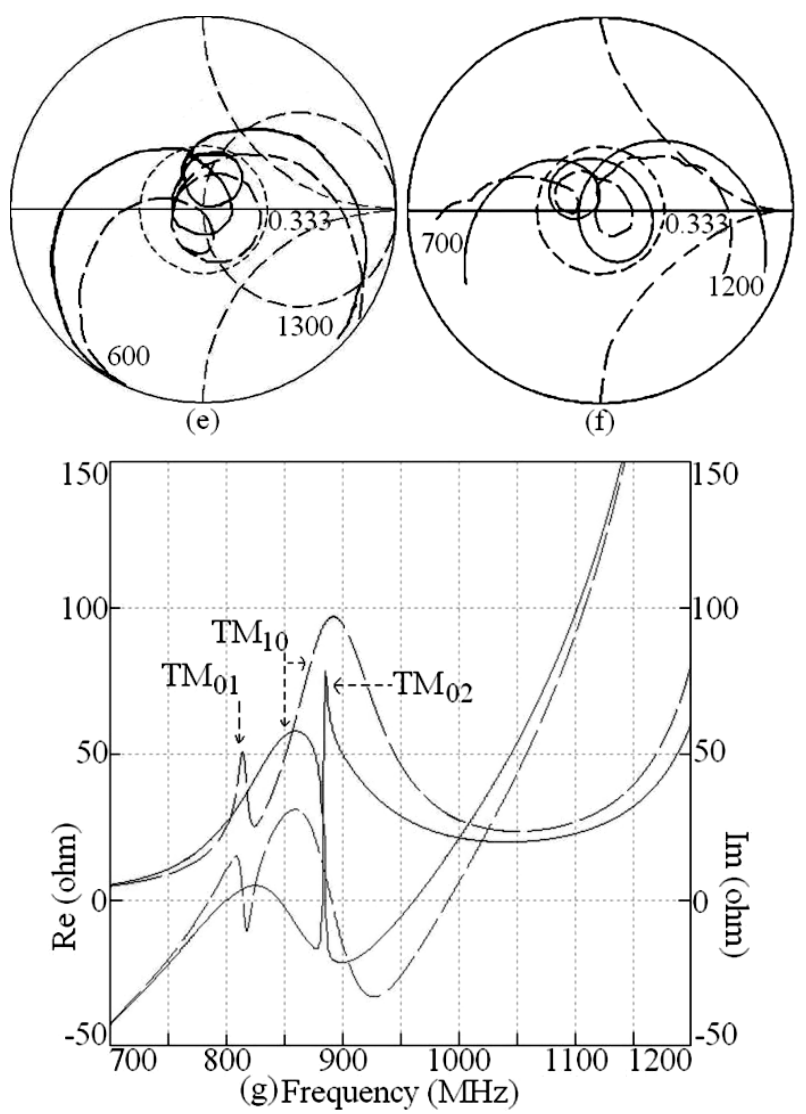

Fig. 4 L-probe fed (a, b) E-shaped MSA and (c, d) half Eshaped MSA [8], input impedance plots for (e) E-shaped and (f) half E-shaped MSA, (-) simulated, (--) measured, and their $(\mathrm{g})$ resonance curve plots, $(-)$ Eshaped MSA, (- -$)$ half E-shaped MSA 


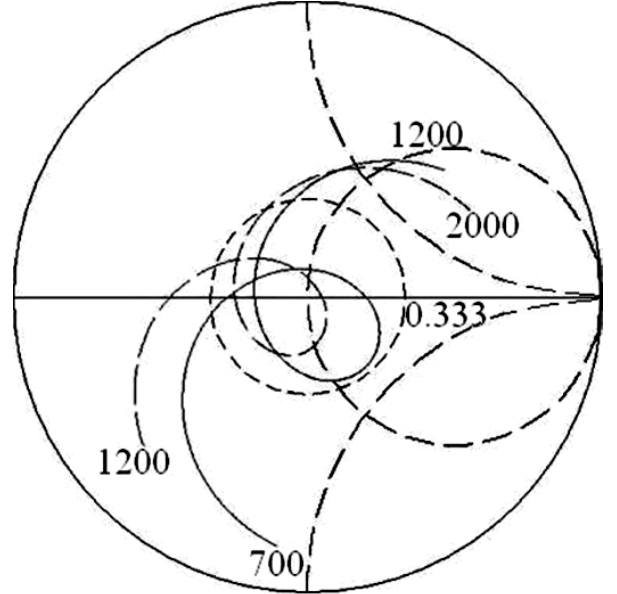

(a)

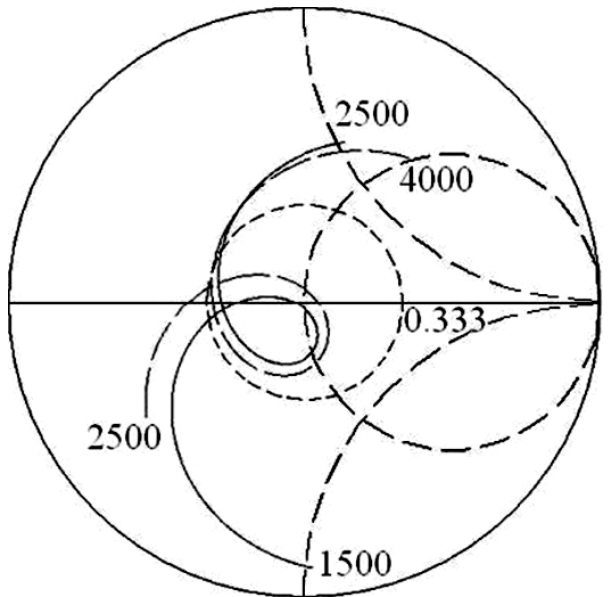

(b)

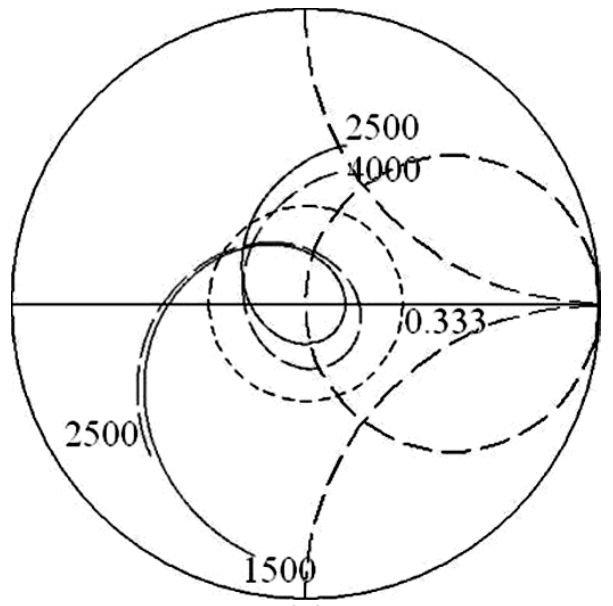

(c)

Fig. 5 Input impedance plots for L-probe fed RMSA at (a) (-) $900 \mathrm{MHz},(--) 1500 \mathrm{MHz}$, and (b) (-) $2000 \mathrm{MHz}$ $(--) 3000 \mathrm{MHz}$, and for CMSA for (c) (-) $2000 \mathrm{MHz}$, (一-) $3000 \mathrm{MHz}$

Further at $900 \mathrm{MHz}$, L-probe fed RMSA is designed such that its vertical probe length is $0.06 \lambda_{0}$. To optimize for broader $\mathrm{BW}$, horizontal length of L-probe is varied. To realize loop formed in the impedance locus inside VSWR $=2$ circle, the total L-probe length was found to be $1.08 \mathrm{~cm}$. To this length fringing field extension length is added, which give total L- probe length to be $0.29 \lambda_{0}$. Similar result is obtained for CMSA with reduced vertical L-probe length.

To compare between two non-contact feeding techniques, at $900 \mathrm{MHz}$, proximity fed RMSA is optimized for broader BW. It yields simulated and measured $\mathrm{BW}$ of around $304 \mathrm{MHz}$ $(32 \%)$. This is the same as that BW given by equivalent Lprobe RMSA as given in Table 1 . The radiation pattern at center frequency of BW in L-probe and proximity fed RMSA in the bore-sight direction is shown in Fig. $6(a, b)$. The two methods give nearly the same pattern with lower cross polarization levels. Thus to compare, in terms of BW, radiation pattern and gain, they give identical response, but proximity feeding is simpler to be implemented as compared to L-probe feeding, especially in thicker substrates.

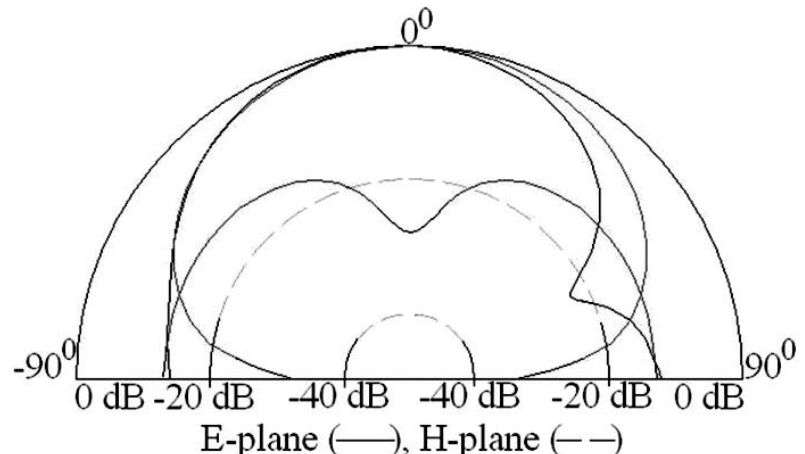

(a) $\mathrm{f}=950 \mathrm{MHz}$

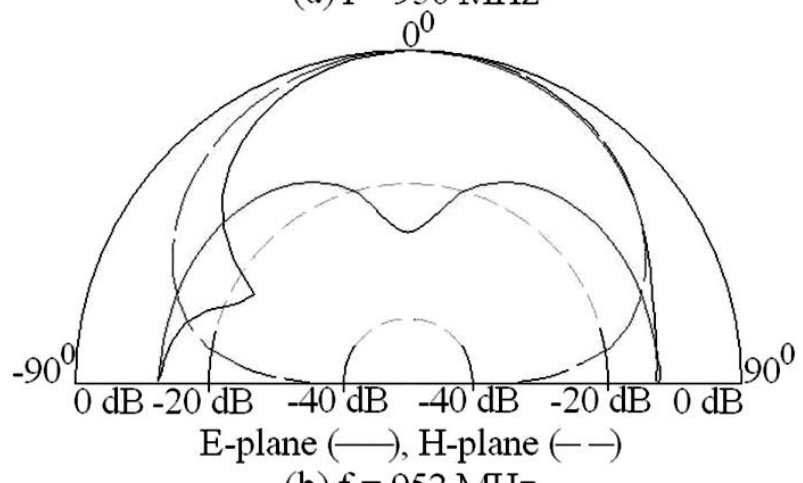

(b) $\mathrm{f}=952 \mathrm{MHz}$

Fig. 6 Radiation pattern plots for (a) L-probe and (b) proximity fed RMSA at center frequency of $\mathrm{BW}$

Table 1 Comparison between various L-probe fed MSAs

\begin{tabular}{|c|c|c|c|}
\hline Configuration & $\begin{array}{c}\text { Simulated } \\
\mathrm{BW} \\
\mathrm{MHz}, \%\end{array}$ & $\begin{array}{c}\text { Measured } \\
\mathrm{BW} \\
\mathrm{MHz}, \%\end{array}$ & $\begin{array}{c}\text { L-probe } \\
\text { length in } \\
\text { terms of } \lambda_{0}\end{array}$ \\
\hline $\begin{array}{c}\text { RMSA @ } \\
900 \mathrm{MHz}\end{array}$ & 302,32 & $314,32.4$ & 0.26 \\
\hline $\begin{array}{c}\text { RMSA @ } \\
1500 \mathrm{MHz}\end{array}$ & $408,26.6$ & $424,26.8$ & 0.273 \\
\hline $\begin{array}{c}\text { RMSA @ } \\
2000 \mathrm{MHz}\end{array}$ & $461,22.7$ & $454,22.4$ & 0.262 \\
\hline $\begin{array}{c}\text { RMSA @ } \\
\text { 3000 MHz }\end{array}$ & $754,24.6$ & $768,24.9$ & 0.263 \\
\hline $\begin{array}{c}\text { CMSA @ } \\
2000 \mathrm{MHz}\end{array}$ & $508,24.7$ & $524,24.9$ & 0.21 \\
\hline $\begin{array}{c}\text { CMSA @ } \\
\text { 3000 MHz }\end{array}$ & $1022,33.1$ & $1054,33.2$ & 0.263 \\
\hline
\end{tabular}




\section{CONCLUSIONS}

The reported configurations of broadband L-probe fed RMSA, U-slot cut CMSA, Annular ring MSA, E-shaped MSA and half E-shaped MSAs were studied. In all the configurations the L-probe length for optimum impedance response was found to be nearly quarter wave in length at the patch resonance frequency. Further using quarter wave length approximation of L-probe length, RMSA and CMSAs were designed at different frequencies and thicker substrates. They yields broadband response with the formation of loop inside VSWR $=2$ circle in the input impedance locus. Further a comparison between non-contact L-probe and proximity feeding techniques for MSAs is presented. The two methods yields similar characteristics in terms of $\mathrm{BW}$ and radiation pattern, but proximity feeding technique is simpler to implement using thicker antenna substrates.

\section{REFERENCES}

[1] Bhartia, B., and Bahl, I. J. 1980, Microstrip Antennas, USA.

[2] Garg, R., Bhartia, P., Bahl, I., and Ittipiboon, A., Microstrip Antenna Design Handbook, 2001, Artech House, USA.

[3] Kumar, G., and Ray, K. P. 2003, Broadband Microstrip Antennas, First Edition, USA, Artech House

[4] Wong, K. L. 2002. Compact and Broadband Microstrip Antennas, John Wiley \& sons, Inc., New York, USA

[5] Park, Jongkuk, Na, Huyng-gi, and Baik, S. H. 2004, Design of a Modified L-probe fed Microstrip Patch Antenna, IEEE Antennas and Wireless Propagation Letters, vol. 3, (2004), pp. 117 - 119.

[6] Singh, P., and Kumar, D. 2011, L-strip Proximity fed Broadband Circular Disk Patch Antenna, International Journal of Microwave and Optical Technology, vol. 6, No. 2, (March 2011), pp. 64 - 69.

[7] Guo, Y. X., Luk, K. M., and Lee, K. F. 2001, L-probe Proximity fed Annular Ring Microstrip Antennas, IEEE Transaction on Antennas and Propagation, vol. 49, no. 1, January 2001, pp. $19-21$.

[8] Deshmukh, Amit A., Chine, P. N., and Ray, K. P. 2008, Broadband L-probe fed E-shaped Microstrip Antennas", Proceedings of APSYM - 2008, Dec. 2931, Kochi, India, 2008, pp. $27-31$.
[9] Cock, R. T. and Christodoulou, C. G. 1987. Design of a two layer capacitively coupled, microstrip patch antenna element for broadband applications, IEEE Antennas Propag. Soc. Int. Symp. Dig., vol. 2, (1987), 936-939.

[10] Huynh, T., and Lee, K. F. 1995. Single-Layer SinglePatch Wideband Microstrip Antenna, Electronics Letters, vol. 31, no. 16, (August 1995), 1310-1312.

[11] Guo, Y. X., Luk, K. M., Lee, K. F., and Chow, Y. L. 1998. Double U-slot Rectangular Patch Antenna, Electronics Letters, vol. 34, (1998), 1805 - 1806

[12] Sharma, S. K., and Shafai, L. 2009. Performance of a Novel $\Psi$-Shaped Microstrip Patch Antenna with Wide Bandwidth, IEEE Antennas \& Wireless Propagation Letters, vol. 8, (2009), $468-471$.

[13] Lee, K. F., Yang, S. L. S., Kishk, A. A., and Luk, K. M. 2010. The Versatile U-slot Patch, IEEE Antennas \& Propagation Magazine, vol. 52, no. 1, (February 2010), $71-88$.

[14] Wong, K. L., and Hsu, W. H. 2001. A Broadband Rectangular Patch Antenna with a Pair of wide slits, IEEE Transactions on Antennas \& Propagation, Vol. 49, No. 9, (September 2001), 1345 - 1347.

[15] Yang, F., Zhang, X., Yc, X., and Sammi, Y. R. 2001 Wide-band E-shaped patch antennas for wireless communication, IEEE Transactions on Antennas \& Propagation, vol. 49, no. 7, (July 2001), $1094-1100$.

[16] Deshmukh, Amit A., Joshi, Apurva A., and Tirodkar, T. 2013, Broadband slot cut gap-coupled proximity fed E-shaped Microstrip Antenna, International Journal of Computer Application, vol. 68, no. 17, (April 2013), pp. $15-18$.

[17] Deshmukh, Amit A., Joshi, Apurva A., Jain, Ankita R. and Tirodkar, T. 2013, Broadband Proximity fed Microstrip Antennas, International Journal of Computer Application, vol. 74, no. 4, (July 2013), pp. $30-36$.

[18] IE3D 12.1, 2004. Zeland Software, Freemont, USA

[19] Deshmukh, Amit A., Phatak, Neelam V., N. Shafin, and Ahuja, Rishi. 2013, Analysis of Broadband Eshaped Microstrip Antennas, International Journal of Computer Application, vol. 80, no. 7, (October 2013), pp. $24-29$. 